\title{
Cannabis hyperemesis syndrome: an update on the pathophysiology and management
}

\author{
Abhilash Perisettia, Mahesh Gajendran ${ }^{b}$, Chandra Shekhar Dasaric, Pardeep Bansal' ${ }^{\mathrm{d}}$, Muhammad Azize, \\ Sumant Inamdarf, Benjamin Tharian', Hemant Goyalg
}

University of Arkansas for Medical Sciences, Little Rock, AR; Texas Tech University Health Sciences Center El Paso; Kansas City VA Medical Center; Moses Taylor Hospital and Reginal Hospital of Scranton, Scranton, PA; University of Toledo, HO; The Wright Center for Graduate Medical Education, Scranton, PA, USA

Abstract

\begin{abstract}
Cannabis hyperemesis syndrome (CHS) is a form of functional gut-brain axis disorder characterized by bouts of episodic nausea and vomiting worsened by cannabis intake. It is considered as a variant of cyclical vomiting syndrome seen in cannabis users especially characterized by compulsive hot bathing/showers to relieve the symptoms. CHS was reported for the first time in 2004, and since then, an increasing number of cases have been reported. With cannabis use increasing throughout the world as the threshold for legalization becomes lower, its user numbers are expected to rise over time. Despite this trend, a strict criterion for the diagnosis of CHS is lacking. Early recognition of CHS is essential to prevent complications related to severe volume depletion. The recent body of research recognizes that patients with CHS impose a burden on the healthcare systems. Understanding the pathophysiology of the endocannabinoid system (ECS) remains central in explaining the clinical features and potential drug targets for the treatment of CHS. The frequency and prevalence of $\mathrm{CHS}$ change in accordance with the doses of tetrahydrocannabinol and other cannabinoids in various formulations of cannabis. CHS is unique in presentation, because of the cannabis's biphasic effect as anti-emetic at low doses and pro-emetic at higher doses, and the association with pathological hot water bathing. In this narrative review, we elaborate on the role of the ECS, its management, and the identification of gaps in our current knowledge of CHS to further enhance its understanding in the future.
\end{abstract}

Keywords Cannabis hyperemesis syndrome, cannabis, marijuana, endocannabinoid system

Ann Gastroenterol 2020; 33 (6): 1-8

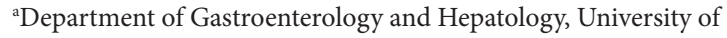
Arkansas for Medical Sciences, Little Rock, AR (Abhilash Perisetti); ${ }^{b}$ Paul L. Foster School of Medicine, Texas Tech University Health Sciences Center El Paso (Mahesh Gajendran); ${ }^{\mathrm{D}}$ Department of Gastroenterology and Hepatology, Kansas City VA Medical Center (Chandra Shekhar Dasari); ${ }^{\mathrm{d} D i v i s i o n}$ of Gastroenterology, Moses Taylor Hospital and Reginal Hospital of Scranton, Scranton, PA (Pardeep Bansal); ${ }^{e}$ Department of Internal Medicine, The University of Toledo, Toledo, $\mathrm{OH}$ (Muhammad Aziz); 'Endoscopy Fellowship, University of Arkansas for Medical Sciences, Little Rock, AR (Sumant

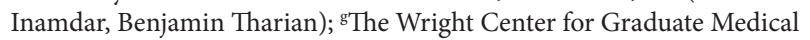
Education, Scranton, PA (Hemant Goyal), USA
\end{abstract}

Conflict of Interest: Hemant Goyal holds stocks in Rimrock Gold Corp., Tauriga Sciences and SinglePoint Inc.

Correspondence to: Hemant Goyal, MD, FACP, Gastroenterology Fellow, The Wright Center for Graduate Medical Education, 501 S. Washington Avenue, Scranton, PA 18505, USA, e-mail: doc.hemant@ yahoo.com

Received 25 April 2020; accepted 16 June 2020; published online 16 September 2020

DOI: https://doi.org/10.20524/aog.2020.0528

\section{Introduction}

Cannabis is the most commonly abused drug in the United States (US). Its use dates back to 3900 BC. However, our understanding of its effects has unfolded significantly over the last 3 decades. The extract of the plant cannabis sativa has been reported to be used for decades in the control of pain and cramps, according to the Chinese literature [1]. Recognition of the function of the endocannabinoid system (ECS) was a breakthrough in explaining the effects of cannabis on different organs, at least in part [2]. The primary psychoactive component of cannabis is tetrahydrocannabinol (THC). These advances enhanced the understanding of cannabinoid (CB) receptors, which led to a better appreciation of the role of cannabis in inflammation, seizures, emesis, and as an appetite stimulant. There is a growing body of research showing the benefit of cannabis in the aforementioned disorders, and its legalization will further augment research on understanding its critical role in new drug developments $[3,4]$. However, these changes also come with substantial risks regarding its adverse effects, such as 
paradoxical hyperemesis, intoxication and behavioral changes (anxiety, panic attacks, and psychoactive changes). Prolonged cannabis use can also result in dependency. Approximately 9\% of individuals who use cannabis report dependence at some point in their use [5]. Cannabis can paradoxically act as an antiemetic during acute ingestion at low doses, whereas persistent high-dose ingestion could result in vomiting, a behavior similar to cyclical vomiting [6]. It appears from the current literature that the prevalence of cannabis hyperemesis syndrome (CHS) is higher in the US compared to Canada and the United Kingdom, although the prevalence of cannabis use is similar in these countries [7,8]. It is unclear whether the increased legalization of cannabis has also contributed to these findings, but this certainly could be a possibility. Hence, raising the awareness of $\mathrm{CHS}$ with an understanding of its pathophysiology and the potential role of therapeutic agents is paramount.

The term CHS was first used more than a decade ago in 2004 [9]. Since then, several CHS cases have been reported in the literature with clear recognition and association with cannabis [10]. However, given the degree of heterogeneity among these case reports and a need for strict criteria, the Rome IV diagnostic criteria were introduced in the category of functional gut disorders. The Rome IV committee defines functional gastrointestinal disorders as disturbances in the gut-brain axis without an organic pathology to explain those symptoms [7]. This functional nausea and vomiting symptom complex may be cyclical or chronic in nature. A strict definition of CHS is lacking; therefore, it is also sometimes considered as a variant of cyclical vomiting syndrome (CVS). Rome IV categorizes CHS as an extension of CVS, with symptom onset associated with heavy cannabis use. It defines CHS as episodic nausea and vomiting episodes resembling CVS, associated with prolonged and excessive use of cannabis and with the relief of symptoms after sustained cessation of its use. The symptoms may or may not improve with compulsive hot showers [11]. However, details about the chronicity of use and duration of sustained cessation remain unclear. It is challenging to estimate the exact prevalence of CHS because most of the case reports have not used these strict criteria. In this review, we discuss the pathophysiology and treatments, and identify the strict prevalence based on the Rome criteria.

\section{Hyperemesis induced by cannabis}

Cannabis has traditionally been used as an appetite stimulant and antiemetic drug and is FDA approved for chemotherapy-related nausea and vomiting when traditional therapy fails. It has multiple effects on the gastrointestinal system, including secretions, appetite stimulation, modulation of inflammation, and motility [12-14]. However, its use is also associated with CHS, signifying its biphasic effect. Disorders involving the gut-brain axis, such as irritable bowel syndrome, functional dyspepsia, functional nausea, and vomiting disorders, have been shown to be related to abnormalities in psychological status, visceral hypersensitivity, dysfunction of autonomic activity and gastric emptying $[15,8]$. Cannabis consists of more than 100 types of cannabinoidal agents, and its potency is determined by the ratio of THC and other cannabinoidal agents [16]. Therefore, this ratio also determines the toxicity during its use. The role of cannabis's antiemetic activity is demonstrated in both species capable of vomiting (ferrets, least shrews, musk shrews) and those that are not, such as rodents [17-19]. In shrews and ferrets, anandamide (AEA) and arachidonolyglycerol (2-AG) reduce emesis in a dose-dependent fashion. $\mathrm{CB}$ agonists (both natural and synthetic) and transient receptor potential cation channel subfamily V member 1 (TRPV1) agonists have demonstrated antiemetic effects $[17,20]$. In animals such as rodents, which lack a vomiting reflex, indirect markers of vomiting are used (taste avoidance, conditioned gaping, change in the facial expression). Cannabinoids reduced these behaviors in rodents suggestive of their anti-emetic effect [18].

Understanding the ECS and its effects on the vomiting center of the brain are fundamental to explain the effect of cannabis for this biphasic response [21]. The ECS is composed of ligands, receptors, signaling, and enzymes (its regulators and inhibitors) [22].

1. Ligands: Ligands in the ECS are produced during the stress response and bind to their receptors (Table 1). These ligands can be classified into either endogenous or exogenous types. Exogenous ligands include $\mathrm{N}$-acyl ethanolamines and mono-acyl-glycerols. Several hundreds of CB agonists and antagonists exist that can potentially act on receptors. Some of the most commonly known exogenous ligands include THC (made of a dibenzopyran ring), cannabidiol, cannabigerol, and cannabinol [23]. They bind to receptors such as G protein-coupled receptors (GPR) GPR18 and GPR55, peroxisome proliferator-activated receptors (PPARs), and TRPV1 [24]. Endogenous ligands are AEA and 2-AG, derived from arachidonic acid; 2-AG has significantly high concentrations in the brain and is mainly involved in signaling. Both of these endogenous ligands are produced

Table 1 Ligands and receptors of the endocannabinoid system

\begin{tabular}{|c|c|}
\hline Major ligands & Minor ligands \\
\hline 2- arachidonolyglycerol & $\mathrm{N}$-arachidonoyl-dopamine \\
\hline $\begin{array}{l}\mathrm{N} \text {-arachidonoyl ethanolamine } \\
\text { anandamide }\end{array}$ & $\begin{array}{l}\text { Noladin ether } \\
\text { Virodhamine }\end{array}$ \\
\hline CB1 Receptors & CB2 Receptors \\
\hline $\begin{array}{l}\text { Location: Predominately in the } \\
\text { brain }\end{array}$ & $\begin{array}{l}\text { Predominately in splenic } \\
\text { macrophages. Minor } \\
\text { location in the brain. }\end{array}$ \\
\hline $\begin{array}{l}\text { Type: GPCR. Located in the plasma } \\
\text { membrane. Other areas of the cell } \\
\text { (mitochondria, intracellular space, } \\
\text { lysosome, and endosome) }\end{array}$ & $\begin{array}{l}\text { GPCR. Located in the } \\
\text { plasma membrane }\end{array}$ \\
\hline $\begin{array}{l}\text { Function: Anxiety, depression and } \\
\text { appetite control, secretions from } \\
\text { gastrointestinal tract, hepatic } \\
\text { metabolism, cardiac dysfunction }\end{array}$ & $\begin{array}{l}\text { Nociception, inflammation, } \\
\text { and addiction }\end{array}$ \\
\hline
\end{tabular}


on demand from cell membrane lipids [25]. AEA and 2-AG are transported from intracellular to extracellular space by diffusion, endocytosis, carrier transport, translocation and possible heat shock proteins [26]. They are involved in the stimulation of $\mathrm{CB}$ receptors in the pre- and post-synaptic areas in the brain (multiple areas including the temporal lobe, orbitofrontal cortex, insula, and parahippocampal) to produce their effects [27].

2. Receptors: The 2 primary $\mathrm{CB}$ receptors are type 1 (CB1) and type 2 ( $\mathrm{CB} 2) . \mathrm{CB} 1$ is present predominately in the brain, where it affects appetite, food control and cognition, along with addiction [25]. CB2 is mainly involved in pain and inflammation control. Additional receptors on which CBs can act include TRPV1, PPAR $\alpha$, GRP55, and GRP119. Vagal control of gut motor functions such as nausea and vomiting is regulated by the endocannabinoids acting on the brainstem via CB1, CB2 and TRPV1 receptors.

3. Signaling: 2-AG exerts its action by retrograde signaling (Fig. 1). Calcium signaling and TRPV1 channel are also involved, especially with AEA. TRPV1 channels (also known as the capsaicin receptor and vanilloid receptor 1) are affected by capsaicin, used as a possible therapeutic modality for CHS [24].

4. Enzymes: AEA and 2-AG are synthesized from membrane lipids on demand [28]. Diacylglycerol (DAG) is split by DAG lipase, resulting in the production of 2-AG. N-acyl- phosphatidylethanolamine is split by phospholipase-D, resulting in the synthesis of AEA. Both these conversions are mediated by a calcium-sensitive rate-limiting step [29]. Inactivation of both AEA and 2-AG occurs intracellularly. For example, 2-AG is hydrolyzed predominately by monoacylglycerol lipase (MAG), while AEA is predominately degraded by the fatty acid amide hydrolase (FAAH) pathway. MAG is localized in the mucosa and muscle layers of duodenum, ileum, proximal and distal colon. FAAH is located in myenteric plexus in the whole gut [30,31]. AEA levels drop during stress, and increasing the levels of AEA (by inhibiting its degradation) could be a potential therapeutic target.

\section{ECS and CHS}

The ECS is actively involved in motility, secretions, emesis, satiety and inflammation [32]. The underlying mechanism of the cannabis-induced biphasic effect related to emesis is not clearly understood, but the literature supports the role of the brainstem and hypothalamic-pituitary-adrenal (HPA) axis. The possible mechanisms described include changes in the density of the receptors, interaction with active cannabis metabolites, the potency of agents, disequilibrium with the hypothalamic-gut axis, and interactions with active agents

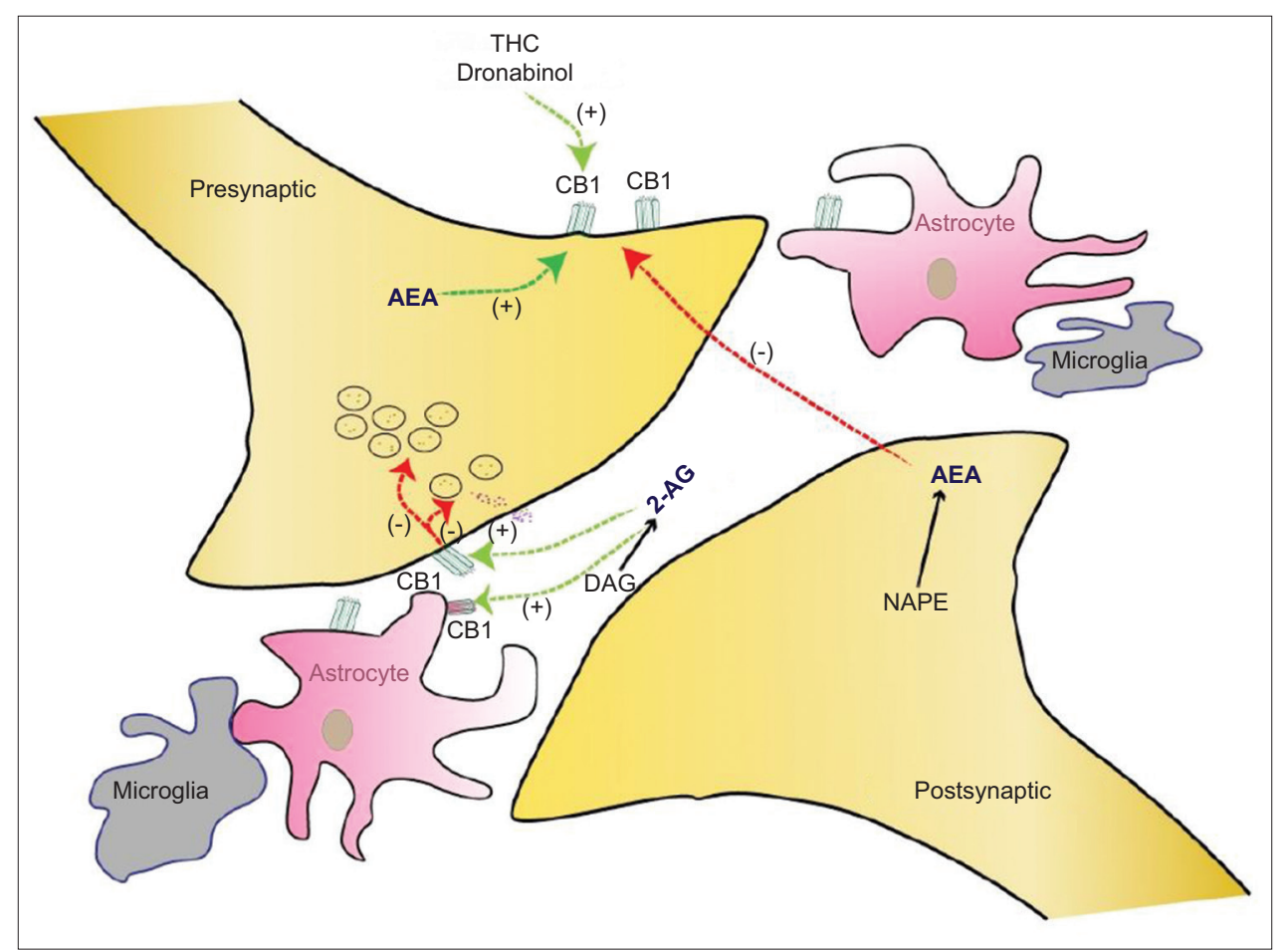

Figure 1 Endocannabinoid system (ECS) with cannabinoid receptors (CB-1, CB-2) and enzymes involved in synthesis and degradation. Anandamide (AEA) \& 2-AG (arachidonolyglycerol) both derived from arachidonic acid. 2-AG is significantly higher concentraion in the brain. It inhibits neurotransmitter release (by binding to CB-1 and by affecting Ca+ metabolism in neurons). CB-1 (brain predominately; also in smalll amounts in GI-enteric NS, NEC, enterocytes [affects permeability and motility], heart [myocytes], skeletal muscle, liver, reproductive system, and affarent pain nerve fibers). CB-2 predominately in macrophages in the spleen and small amounts in CNS peripheral tissues, Both are G-coupled receptors (GPCR) 
(explained below) [33]. It could be a combination of these that produces the various clinical effects of cannabis. ECS affects nausea and vomiting pathways in multiple ways, as noted in Fig. 2.

A. Antiemetic activity: ECS plays an important neuromodulator of nausea and vomiting, especially during stress response [34]. Nausea and vomiting during a stress phenomenon (chemotherapy, migraine, motion sickness) are predominately mediated by brainstem nuclei, HPA and the vagus nerve [35,36] (Fig. 2). The ECS provides negative feedback for the HPA axis, and decreased effects of ECS during stress are known to increase HPA activity [37]. This increased activity of HPA via the vagus nerve produces emesis. The mechanism by which ECS inhibition occurs is unknown, although activation of $\mathrm{CB} 1$ receptors in the central nervous system (CNS) is the most likely pathway. As CB1 receptors are predominately present in the CNS, their levels also drop during stress [17]. Individuals with acute motion sickness showed significantly higher stress scores with lower endocannabinoid levels. Serum levels of AEA have been shown to drop during motion sickness. Thus, increasing the blood levels of AEA by inhibition of its degradation by FAAH can improve nausea and vomiting [34]. As endocannabinoid activity is lowered in stress response, enhancing ECS signaling could be used as a potential anti-emetic strategy. This mechanism has been shown to improve nausea and vomiting induced by cisplatin and nicotine [36].

B. Pro-emesis activity: THC in higher amounts can cause intoxication, resulting in paradoxical pro-emetic characteristics. THC is stored in fat cells in the body. Stress and food-deprivation stimulate the sympathetic nervous system, which increases lipolysis to meet body demands mediated by the action of adrenocorticotrophic hormone
(ACTH) on adipocyte receptors [38]. Increased ACTH enhances the release of THC stored in adipocytes, leading to emesis. Therefore, higher THC levels (after heavy ingestion of cannabis with highly potent THC) can explain its proemetic activity. Furthermore, the presence of stress or food deprivation can raise THC levels (reintoxication) [39].

C. Combined activity: The potency of cannabis is directly related to the ratio of THC and cannabidiol in the preparation. As ingestion cannabis includes a variety of compounds, its potency directs the type of activity (anti-emetic or pro-emetic). In addition to THC metabolites, cannabis has multiple other CBs (cannabidiol, cannabigerol), which play a role in the initiation of emesis. The high potency of some cannabis preparations explains the biphasic effect of cannabis, i.e., anti-emetic at low doses and pro-emetic at higher ones [40]. However, there are still considerable gaps in our knowledge as regards the in healthy vs. diseased state, genetic predisposition, downregulation of $\mathrm{CB}$ receptors among chronic cannabis users, and what role they play in the emesis and inter-emesis period.

\section{Diagnosis}

CHS is traditionally diagnosed as the presence of hyperemesis in the setting of chronic cannabis use associated with pathological hot bathing behaviors. However, there has been considerable heterogeneity in previous literature with respect to categorizing patients with this diagnosis. CHS involves 3 phases: prodromal, hyperemetic and recovery. The prodromal phase is characterized by nausea, abdominal discomfort and fear of vomiting. The hyperemetic phase

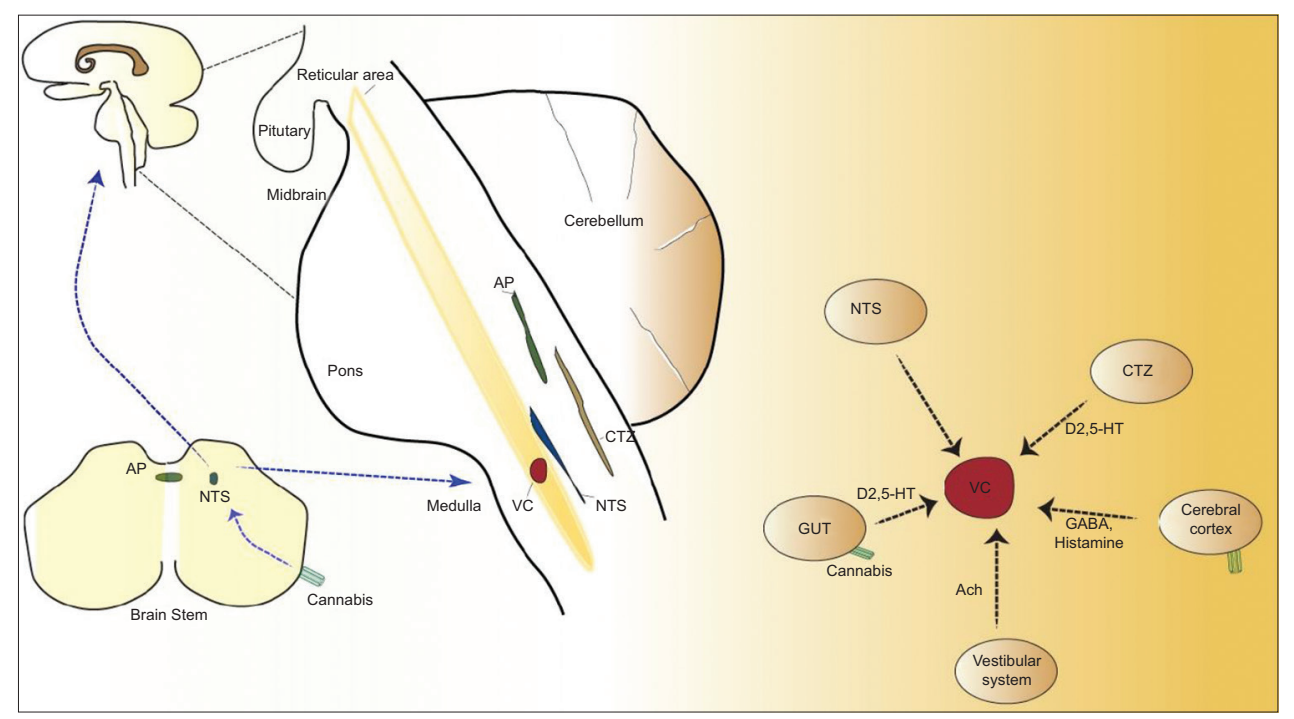

Figure 2 Pathways involving cannabis on the central nervous system. After the ingestion of cannabis, the active componenet binds to CB1 receptors in the spinal cord and brain stem. It affects signaling at Nucleus Tractus Solitarius (NTS), which affects the vomiting center (VC, located in the medulla oblongata of the brain stem) and thalamus. Various brain stem nuclei depicted with interaction with the vomiting center. Dorsal vagal complex (composed of area postrema and NTS) is affected by cannabis. Right panel showing vomiting center with different affecters (and neurotransmitters) of the VC. CTZ (Chemoreceptor trigger zone); AP-Area Postrema; VC-Vomiting center 
includes intense and multiple episodes of vomiting, which bring the patient to medical attention. After symptoms improve, the recovery phase starts with the establishment of normal eating behaviors [41,42]. Episodic nausea and vomiting occur with a history of chronic use of cannabis [43]. Under-recognition of this disorder can lead to multiple investigations with increased healthcare expenses $[44,45]$. Sometimes, patients may also report a recent increase in cannabis use or a change in their source of cannabis purchase, which could indicate a change in the potency of cannabis. Some patients report relief of their symptoms with compulsive use of hot showers. Other disorders, such as Addison's disease, migraine headaches, hyperemesis of pregnancy, bulimia, and psychogenic vomiting [46], can also mimic these symptoms. However, these diagnoses can also coexist with CHS [47].

A thorough history, physical examination and directed testing of differential diagnoses may assist in ruling out these diagnoses. The Rome IV criteria provide some objectivity to

Table 2 Rome IV criteria for cannabis hyperemesis syndrome

\begin{tabular}{|c|c|}
\hline Required criteria [8] & Comments \\
\hline $\begin{array}{l}\text { 1. Symptoms present for past } 3 \text { months } \\
\text { (with onset at least } 6 \text { months prior) } \\
\text { 2. Stereotypical episodes lasting } \\
<1 \text { week } \\
\text { 3. At least } 3 \text { episodes in last } 1 \text { year } \\
\text { and } 2 \text { episodes in last } 6 \text { months } \\
\text { (occurring at least } 1 \text { week apart) } \\
4 \text {. No vomiting between episodes. } \\
\text { Milder symptoms can be present } \\
\text { during this. } \\
\text { All these criteria should be associated } \\
\text { with chronic use of cannabis and stop } \\
\text { after its cessation }\end{array}$ & $\begin{array}{l}\text { Definition of chronic use } \\
\text { needs more elaboration } \\
\text { Cessation of cannabis } \\
\text { use needs to be defined } \\
\text { for an exact period }\end{array}$ \\
\hline
\end{tabular}

help with the diagnosis by placing CHS under the heading of functional gut-brain disorders, and consider it as a variant of CVS (Table 2). Venkatesan et al have proposed a new criterion for CHS with the use of clinical features, cannabis use patterns including duration and frequency, and symptoms resolution after at least 6 months of cessation [48]. However, questions remain about the dosage of cannabis, individual and genetic susceptibility, abstinence period and the inclusion of abdominal pain as a criterion. The clinical effects of volume depletion dominate complications related to CHS. Reports of severe volume depletion resulting in acute kidney injury and severe electrolyte disturbances with rhabdomyolysis have been reported in the literature [49]. Severe and persistent vomiting can also lead to Mallory-Weiss tear [47].

\section{Pathological bathing behavior}

Multiple studies report pathological frequent and prolonged hot shower behaviors with CHS. It is a learned trait by the patients to obtain relief from some of the symptoms of CHS and a few reports even describe CHS as "cannabis shower syndrome." Some other reports have considered this behavior as a firm requirement and potentially pathognomonic for CHS [50]. Hot showers have been reported to assist in stabilizing the hypothalamic thermostat, frequently altered by chronic cannabis use [51]. Accordingly, they have been reported as one of the therapeutic modalities for the management of the CHS. However, this mechanism has never been tested nor challenged. Further, these behaviors could also be noted in CVS, preadolescents, and adolescents with no prior exposure to cannabis [8]. These changes from

Table 3 Treatment options for cannabis hyperemesis syndrome

\begin{tabular}{|c|c|c|}
\hline Therapy & Mechanism and advantages & Adverse effects \\
\hline Benzodiazepines $[67,68]$ & $\begin{array}{l}\text { Useful for their anti-anxiety, anti-emetic and inhibition } \\
\text { of vestibular system }\end{array}$ & Sedation, altered consciousness \\
\hline TCA [69] & Used prophylactically. Mixed results noted. & Arrhythmias \\
\hline $\begin{array}{l}\text { Anti-dopaminergic: } \\
\text { Haloperidol }[53,70] \\
\text { Droperidol }[59]\end{array}$ & $\begin{array}{l}\text { Haloperidol is a broad spectrum antiemetic. May } \\
\text { interfere with CB1 signaling [54]. } \\
\text { Blockage of dopamine at the chemoreceptor trigger } \\
\text { zone. }\end{array}$ & $\begin{array}{l}\text { Arrhythmias, central nervous system side } \\
\text { effects } \\
\text { Dysrhythmias (QT prolongation), } \\
\text { oversedation }\end{array}$ \\
\hline $\begin{array}{l}\text { Dopaminergic agents: } \\
\text { Promethazine and } \\
\text { prochlorperazine [71] }\end{array}$ & Effect CTZ area in the brain stem. Variable success noted & $\begin{array}{l}\text { Arrhythmias, extrapyramidal effects, } \\
\text { hypotension, and sedation related effects }\end{array}$ \\
\hline $\begin{array}{l}\text { Serotonergic } \\
\text { antagonists: } \\
\text { Ondansetron [54] }\end{array}$ & $\begin{array}{l}\text { First-line agents used for emesis. Variable response } \\
\text { noted }[54,72]\end{array}$ & Arrhythmias \\
\hline Corticosteroids [73] & Rarely used with limited response $[55,74]$ & Hyperglycemia and psychosis \\
\hline Capsaicin $[74,75]$ & Bind to TRPV1 receptors in proximity to CB1 [62] & Minimal. Skin irritation \\
\hline Volume repletion & Prevents dehydration related symptoms & Minimal \\
\hline Cannabis cessation $[64]$ & Required for long-term management & Patient compliance \\
\hline
\end{tabular}


Table 4 Gaps in our understanding of CHS

\begin{tabular}{|l|l|}
\hline Component & Elements which need attention \\
\hline Definition & $\begin{array}{l}\text { Need further research and optimization of } \\
\text { classification criteria }\end{array}$ \\
\hline Pathophysiology & $\begin{array}{l}\text { More elaboration of biphasic effect. Role of } \\
\text { minor cannabinoid ligands and receptors. } \\
\text { Further feedback mechanism of HPA and ECS } \\
\text { systems with their precise role in CHS }\end{array}$ \\
\hline Dosing & $\begin{array}{l}\text { Precise dosing measurements need to elicit } \\
\text { CHS response and intoxication by THC }\end{array}$ \\
\hline Potency & $\begin{array}{l}\text { Identifying the thresholds for the potency of } \\
\text { THC to cannabinoid ratio to evaluate its role } \\
\text { in CHS pathogenesis }\end{array}$ \\
\hline Treatment & $\begin{array}{l}\text { Standardizing primary first and second-line } \\
\text { agents }\end{array}$ \\
\hline
\end{tabular}

$\overline{C H S, ~ c a n n a b i s ~ h y p e r e m e s i s ~ s y n d r o m e ; ~ H P A, ~ h y p o t h a l a m i c-p i t u i t a r y-a d r e n a l ; ~}$ ECS, endocannabinoid system; THC, tetrahydrocannabinol

hot bathing are probably not specific to CHS but can be seen across all functional nausea and vomiting disorders, including CVS, and are probably aggravated by cannabis use [9]. Thus, hot shower bathing may be more closely related to CHS, but is neither specific nor sensitive in its diagnosis. This is probably the reason for its non-inclusion in the Rome IV diagnostic criteria for CHS.

\section{Management}

CHS management primarily depends on the severity of the symptoms, the development of complications, and the prevention of further recurrence. Previous reports showed that the usual antiemetic agents, such as ondansetron, prochlorperazine, and promethazine, are not as effective [52]. Various treatment options have been tried in CHS, outlined in Table 3. In light of the unresponsiveness to the usual antiemetic agents, benzodiazepines, tricyclic antidepressants (TCA), capsaicin and corticosteroids have been tried with variable results [53-56]. Given the promising results from intravenous haloperidol, a double-blind, randomized controlled trial comparing it to ondansetron is currently underway [57]. Droperidol use has been reported rarely in CHS, probably because its use in the US has been restricted since the 2001 Food and Drug Administration black box warning about potential QT prolongation [58]. Nevertheless, droperidol is associated with less use of antiemetics and shorter total hospital stays [59]. Various mechanisms are involved in the cessation of symptoms via dopaminergic, serotoninergic, substance $\mathrm{P}$ and TRPV1 signaling. The prophylactic use of TCA for CVS has shown mixed response for the treatment of symptoms, with or without the use of cannabis [60].

Capsaicin is a topical agent that exerts its action via TRPV1 and has shown efficacy in the treatment of CHS [61]. Capsaicin has high specificity to these receptors and inhibits the release of substance $\mathrm{P}$ in the nucleus tractus solitarius and the area postrema of the brain stem [62]. The use of capsaicin was associated with a reduction in opioids and total medical requirement in the treatment of CHS [63]. Minimal side effects, including skin irritation, have been noted. TPRV1 receptors can be activated at temperatures above $43^{\circ} \mathrm{C}$, which could partly explain why pathological hot bathing can provide temporary relief in CHS [52].

The long-term treatment of CHS involves complete cessation of cannabis use and potentially a rehabilitation program. However, this requires significant effort on the patient's part [64]. The precise duration of cessation of cannabis is unknown, but has been reported to be from at least 3 months to 4 years $[65,66]$. This is in part due to the long halflife of THC, owing to its storage in the adipose tissue. As we acquire more data, the exact duration of cessation might be worth exploring (Table 4). It might help to refine the Rome IV criteria for the improvement of symptoms related to cannabis cessation. Furthermore, patients should be educated about the paradoxical effects of hyperemesis associated with cannabis, which could assist in the early identification of symptoms and prompt medical attention.

\section{Concluding remarks}

CHS is an important manifestation of long-term cannabis use associated with episodic nausea and vomiting, similar to CVS. Rome IV criteria provide objectivity to CHS diagnosis as significant heterogeneity was noted in the previous cases for its diagnosis. Despite this, Rome IV may underestimate CHS cases because of the lack of details about the definition of chronic use and the duration of cannabis abstinence. Pathological hot water bathing is seen in CHS patients more often than in functional nausea and vomiting, but it is neither sensitive nor specific for CHS. The ECS and ratio of THC to CBs provide important insights about cannabis's biphasic effect on emesis, and its role in affecting brain stem and HPA axis signaling. The management of CHS is mainly conservative, with aggressive volume repletion, use of antiemetics, and cannabis cessation with rehabilitation. The prevalence of cannabis use disorder is poised to increase with the decrease in its legal thresholds for recreational use. Raising awareness and availability of further CHS data in the future will pave the way for targeted novel therapeutic interventions for CHS.

\section{References}

1. Li H-L. An archaeological and historical account of cannabis in China. Economic Botany 1974;28:437-448.

2. Devane WA, Hanus L, Breuer A, et al. Isolation and structure of a brain constituent that binds to the cannabinoid receptor. Science 1992;258:1946-1949.

3. Bonini SA, Premoli M, Tambaro S, et al. Cannabis sativa: A comprehensive ethnopharmacological review of a medicinal plant with a long history. J Ethnopharmacol 2018;227:300-315.

4. Madireddy S, Patel RS, Ravat V, et al. Burden of Comorbidities in Hospitalizations for Cannabis Use-associated Intractable Vomiting 
during Post-legalization Period. Cureus 2019;11.

5. Silins E, Horwood LJ, Patton GC, et al. Young adult sequelae of adolescent cannabis use: an integrative analysis. The Lancet Psychiatry 2014;1:286-293.

6. Ruffle JK, Bajgoric S, Samra K, Chandrapalan S, Aziz Q, Farmer AD. Cannabinoid hyperemesis syndrome: an important differential diagnosis of persistent unexplained vomiting. Eur J Gastroenterol Hepatol 2015;27:1403-1408.

7. Drossman DA, Hasler WL. Rome IV-functional GI disorders: disorders of gut-brain interaction. Gastroenterology 2016;150:1257-1261.

8. Aziz I, Palsson OS, Whitehead WE, Sperber AD, Simrén M, Törnblom H. Epidemiology, clinical characteristics, and associations for Rome IV functional nausea and vomiting disorders in adults. Clin Gastroenterol Hepatol 2019;17:878-886.

9. Allen J, De Moore G, Heddle R, Twartz J. Cannabinoid hyperemesis: cyclical hyperemesis in association with chronic cannabis abuse. Gut 2004;53:1566-1570.

10. Deceuninck E, Jacques D. Cannabinoid hyperemesis syndrome: a review of the literature. Psychiatr Danub 2019:390-394.

11. Stanghellini V, Chan FK, Hasler WL, et al. Gastroduodenal disorders. Gastroenterology 2016;150:1380-1392.

12. Patel RS, Goyal H, Satodiya R, Tankersley WE. Relationship of cannabis use disorder and Irritable Bowel Syndrome (IBS): An analysis of 6.8 million hospitalizations in the United States. Subst Use Misuse 2020;55:281-290.

13. Perisetti A, Bansal P, Goyal H. Recreational Marijuana Use and Bowel Function. Am J Gastroenterol 2020;

14. Perisetti A, Rimu AH, Khan SA, Bansal P, Goyal H. Role of cannabis in inflammatory bowel diseases. Annals of Gastroenterology 2020;33:134.

15. Goyal H, Rahman MR, Perisetti A, Shah N, Chhabra R. Cannabis in liver disorders: a friend or a foe? Eur J Gastroenterol Hepatol 2018;30:1283-1290.

16. Atakan Z. Cannabis, a complex plant: different compounds and different effects on individuals. Therapeutic advances in psychopharmacology 2012;2:241-254.

17. Van Sickle MD, Duncan M, Kingsley PJ, et al. Identification and functional characterization of brainstem cannabinoid CB2 receptors. Science 2005;310:329-332.

18. Abalo R, Vera G, López-Pérez AE, Martínez-Villaluenga M, Martín-Fontelles MI. The gastrointestinal pharmacology of cannabinoids: focus on motility. Pharmacology 2012;90:1-10.

19. Rock EM, Parker LA. Cannabinoids as potential treatment for chemotherapy-induced nausea and vomiting. Front Pharmacol 2016;7:221.

20. Sharkey K, Cristino L, Oland L, et al. Arvanil, anandamide and $\mathrm{N}$-arachidonoyl-dopamine (NADA) inhibit emesis through cannabinoid CB1 and vanilloid TRPV1 receptors in the ferret. Eur J Neurosci 2007;25:2773-2782.

21. Pacher P, Bátkai S, Kunos G. The endocannabinoid system as an emerging target of pharmacotherapy. Pharmacol Rev 2006;58:389-462.

22. Pertwee RG. Pharmacology of cannabinoid CB1 and CB2 receptors. Pharmacol Ther 1997;74:129-180.

23. Bow EW, Rimoldi JM. The structure-function relationships of classical cannabinoids: CB1/CB2 modulation. Perspect Medicin Chem 2016;8:PMC. S32171.

24. Storozhuk MV, Zholos AV. TRP channels as novel targets for endogenous ligands: focus on endocannabinoids and nociceptive signalling. Curr Neuropharmacol 2018;16:137-150.

25. Di Marzo V, Stella N, Zimmer A. Endocannabinoid signalling and the deteriorating brain. Nature Reviews Neuroscience 2015;16:30-42.

26. Kano M, Ohno-Shosaku T, Hashimotodani Y, Uchigashima M, Watanabe M. Endocannabinoid-mediated control of synaptic transmission. Physiol Rev 2009;
27. Battistella G, Fornari E, Annoni J-M, et al. Long-term effects of cannabis on brain structure. Neuropsychopharmacology 2014;39:2041-2048.

28. Di Marzo V. The endocannabinoid system: its general strategy of action, tools for its pharmacological manipulation and potential therapeutic exploitation. Pharmacol Res 2009;60:77-84.

29. Murataeva N, Straiker A, Mackie K. Parsing the players: 2arachidonoylglycerol synthesis and degradation in the CNS. $\mathrm{Br} J$ Pharmacol 2014;171:1379-1391.

30. Duncan M, Davison J, Sharkey K. Endocannabinoids and their receptors in the enteric nervous system. Aliment Pharmacol Ther 2005;22:667-683.

31. Duncan M, Thomas AD, Cluny NL, et al. Distribution and function of monoacylglycerol lipase in the gastrointestinal tract. American Journal of Physiology-Gastrointestinal and Liver Physiology 2008;295:G1255-G1265.

32. Hornby PJ, Prouty SM. Involvement of cannabinoid receptors in gut motility and visceral perception. Br J Pharmacol 2004;141:1335-1345.

33. Sorensen CJ, DeSanto K, Borgelt L, Phillips KT, Monte AA. Cannabinoid hyperemesis syndrome: diagnosis, pathophysiology, and treatment-a systematic review. J Med Toxicol 2017;13:71-87.

34. Choukèr A, Kaufmann I, Kreth S, et al. Motion sickness, stress and the endocannabinoid system. PLosOne 2010;5:e10752.

35. Juhasz G, Lazary J, Chase D, et al. Variations in the cannabinoid receptor 1 gene predispose to migraine. Neurosci Lett 2009; 461:116-120.

36. Parker L, Limebeer C, Rock E, Litt D, Kwiatkowska M, Piomelli D. The FAAH inhibitor URB-597 interferes with cisplatin-and nicotine-induced vomiting in the Suncus murinus (house musk shrew). Physiol Behav 2009;97:121-124.

37. Storr MA, Sharkey KA. The endocannabinoid system and gutbrain signalling. Curr Opin Pharmacol 2007;7:575-582.

38. Meisner H, Carter JJ. Regulation of lipolysis in adipose tissue. Horiz Biochem Biophys 1977;4:91-129.

39. Gunasekaran N, Long L, Dawson B, et al. Reintoxication: the release of fat-stored $\Delta 9$-tetrahydrocannabinol (THC) into blood is enhanced by food deprivation or ACTH exposure. Br J Pharmacol 2009;158:1330-1337.

40. Parker LA, Kwiatkowska M, Burton P, Mechoulam R. Effect of cannabinoids on lithium-induced vomiting in the Suncus murinus (house musk shrew). Psychopharmacology (Berl) 2004;171:156-161.

41. A Galli J, Andari Sawaya R, K Friedenberg F. Cannabinoid hyperemesis syndrome. Current drug abuse reviews 2011;4:241-249.

42. Goyal H, Singla U, Gupta U, May E. Role of cannabis in digestive disorders. Eur J Gastroenterol Hepatol 2017;29:135-143.

43. Attout H, Amichi S, Josse F, Appavoupoule V, Randriajohany A, Thirapathi Y. Cannabis Hyperemesis Syndrome: A Still UnderRecognized Syndrome. European Journal of Case Reports in Internal Medicine 2020;7.

44. Graham C. Cannabis hyperemesis syndrome: still under recognised after all these years. Journal of the Royal College of Physicians of Edinburgh 2019;49:262.

45. Waqas S, Baqi A, Rasheed MA, Kelly E. Cannabis hyperemesis syndrome under recognised across the Irish Sea! JR Coll Physicians Edinb 2019;49:345-346.

46. Abell TL, Adams KA, Boles R, et al. Cyclic vomiting syndrome in adults. Neurogastroenterol Motil 2008;20:269-284.

47. Alaniz VI, Liss J, Metz TD, Stickrath E. Cannabinoid hyperemesis syndrome: a cause of refractory nausea and vomiting in pregnancy. Obstet Gynecol 2015;125:1484-1486.

48. Venkatesan T, Levinthal DJ, Li BU, et al. Role of chronic cannabis use: cyclic vomiting syndrome vs cannabinoid hyperemesis syndrome. Neurogastroenterol Motil 2019;31:e13606.

49. Habboushe J, Sedor J. Cannabinoid hyperemesis acute renal failure: a common sequela of cannabinoid hyperemesis syndrome. Am J 
Emergency Med 2014;32:690. e1-90. e2.

50. Habboushe J, Rubin A, Liu H, Hoffman RS. The prevalence of cannabinoid hyperemesis syndrome among regular marijuana smokers in an urban public hospital. Basic Clin Pharmacol Toxicol 2018;122:660-662.

51. Patterson DA, Smith E, Monahan M, et al. Cannabinoid hyperemesis and compulsive bathing: a case series and paradoxical pathophysiological explanation. J Am Board of Family Medicine 2010;23:790-793.

52. Richards JR, Gordon BK, Danielson AR, Moulin AK. Pharmacologic treatment of cannabinoid hyperemesis syndrome: a systematic review. Pharmacotherapy 2017;37:725-734.

53. Price SL, Fisher C, Kumar R, Hilgerson A. Cannabinoid hyperemesis syndrome as the underlying cause of intractable nausea and vomiting. J Am Osteopathic Association 2011;111:166-169.

54. Desai RI, Thakur GA, Vemuri VK, Bajaj S, Makriyannis A, Bergman J. Analysis of tolerance and behavioral/physical dependence during chronic CB1 agonist treatment: effects of CB1 agonists, antagonists, and noncannabinoid drugs. J Pharmacol Exp Ther 2013;344:319-328.

55. Nogi M, Fergusson D, Chiaco JMC. Mid-ventricular variant takotsubo cardiomyopathy associated with cannabinoid hyperemesis syndrome: a case report. Hawai'i Journal of Medicine and Public Health 2014;73:115.

56. Graham J, Barberio M, Wang GS. Capsaicin cream for treatment of cannabinoid hyperemesis syndrome in adolescents: a case series. Pediatrics 2017;140.

57. ClinicalTrials.gov. Haloperidol Versus Ondansetron for Cannabis Hyperemesis Syndrome (HaVOC) - No Study Results Posted ClinicalTrials.gov- Accessed July 7, 2020. 2020.

58. Richards JR, Schneir AB. Droperidol in the emergency department: is it safe? J Emergency Med 2003;24:441-447.

59. Lee C, Greene SL, Wong A. The utility of droperidol in the treatment of cannabinoid hyperemesis syndrome. Clin Toxicol 2019;57:773-777.

60. Hejazi R, Lavenbarg T, Foran P, McCallum R. Who are the nonresponders to standard treatment with tricyclic antidepressant agents for cyclic vomiting syndrome in adults? Aliment Pharmacol Ther 2010;31:295-301.
61. Yang F, Zheng J. Understand spiciness: mechanism of TRPV1 channel activation by capsaicin. Protein and cell 2017;8:169-177.

62. Dezieck L, Hafez Z, Conicella A, et al. Resolution of cannabis hyperemesis syndrome with topical capsaicin in the emergency department: a case series. Clin Toxicol 2017;55:908-913.

63. Wagner S, Hoppe J, Zuckerman M, Schwarz K, McLaughlin J. Efficacy and safety of topical capsaicin for cannabinoid hyperemesis syndrome in the emergency department. Clin Toxicol 2020;58:471-475.

64. Budney AJ, Roffman R, Stephens RS, Walker D. Marijuana dependence and its treatment. Addict Sci Clin Pract 2007;4:4.

65. Li B, Balint JP. Cyclic vomiting syndrome: evolution in our understanding of a brain-gut disorder. Adv Pediatr 2000;47:117-160.

66. Prakash C, Staiano A, Rothbaum RJ, Clouse RE. Similarities in cyclic vomiting syndrome across age groups. Am J Gastroenterol 2001;96:684-688.

67. Singh P, Kuo B. Central aspects of nausea and vomiting in GI disorders. Curr Treat Options 2016;14:444-451.

68. Figueroa-Rivera IM, Estremera-Marcial R, Sierra-Mercado M, Gutiérrez-Núñez J, Toro DH. Cannabinoid hyperemesis syndrome: a paradoxical cannabis effect. Case Rep Gastrointest Med 2015;2015.

69. Shearer J, Luthra P, Ford AC. Cyclic vomiting syndrome: a case series and review of the literature. Frontline Gastroenterol 2018;9:2-9.

70. Srihari P, Liu M, Punzell S, Shebak SS, Rea WS. Cannabinoid hyperemesis syndrome associated with compulsive showering and acute kidney injury. Prim Care Companion CNS Disord 2016;18:1.

71. Hendren G, Aponte-Feliciano A, Kovac A. Safety and efficacy of commonly used antiemetics. Expert Opin Drug Metab Toxicol 2015;11:1753-1767.

72. Ukaigwe A, Karmacharya P, Donato A. A gut gone to pot: a case of cannabinoid hyperemesis syndrome due to K2, a synthetic cannabinoid. Case Rep Emerg Med 2014;2014.

73. Bonnet U. An overlooked victim of cannabis: losing several years of well-being and inches of jejunum on the way to unravel her hyperemesis enigma. Clin Neuropharmacol 2016;39:53-54.

74. Parekh JD, Wozniak SE, Khan K, Dutta SK. Cannabinoid hyperemesis syndrome. Case Rep 2016;2016:bcr2015213620.

75. Izzo AA, Sharkey KA. Cannabinoids and the gut: new developments and emerging concepts. Pharmacol Ther 2010;126:21-38. 